\title{
WestVirginiaUniversity。
}

Department of Economics

Working Paper Series

\section{Collective Bargaining and School \\ District Test Scores: Evidence from \\ Ohio Bargaining Agreements}

Joshua C. Hall

Donald J. Lacombe

Joylynn Pruitt

Working Paper No. 16-03

This paper can be found at the College of Business and Economics

Working Paper Series homepage: 


\title{
Collective Bargaining and School District Test Scores: Evidence from Ohio Bargaining Agreements
}

\author{
Joshua C. Hall ${ }^{*}$ \\ Associate Professor of Economics, Department of Economics \\ Research Associate, Regional Research Institute \\ West Virginia University \\ 1601 University Ave, PO Box 6025 \\ Morgantown, WV 26506-6025 \\ joshua.c.hall@gmail.com \\ Donald J. Lacombe \\ Associate Professor of Natural Resource Economics and Economics \\ Research Associate Professor, Regional Research Institute \\ Chestnut Ridge Research Building, Room 509 \\ West Virginia University \\ Morgantown, WV 26506 \\ donald.lacombe@mail.wvu.edu \\ Joylynn Pruitt \\ Mary Wollstonecraft Fellow \\ Department of Economics \\ West Virginia University \\ Morgantown, WV 26506 \\ jopruitt@mix.wvu.edu
}

\begin{abstract}
We revisit the relationship between collective bargaining by teachers unions and school performance. The empirical literature in this area has found mixed results at both the state and district levels. We contribute to this literature in two ways. First, rather than simply dummy union status, we proxy for the restrictiveness of collective bargaining agreements with the number of pages per agreement. Second, we employ Bayesian spatial methods to deal with spatial dependence in school district activities. Our reduced-form results indicate that collective bargaining directly lowers scores on high school math scores, but that the total effect is zero.
\end{abstract}

Keywords: collective bargaining; teachers unions; education production function

JEL Codes: J50, H1, I21

\footnotetext{
* The authors would like to acknowledge the Center for Free Enterprise within the College of Business at West Virginia University for general research support such as journal submission fees and travel funding.
} 


\section{Collective Bargaining and School District Test Scores: Evidence from Ohio Bargaining Agreements}

\section{Introduction}

One of the oldest policy debates in the economics of education is the direction of the impact of teachers unions on education production. Research by Eberts and Stone (1987) finds evidence that unionization increases school productivity, while Peltzman (1993) and Hoxby (1996) find the opposite. Eberts (2007) concludes that the literature is mixed in part because different methodological approaches yield different results. Studies done on aggregated data find that unions have a negative effect on student achievement, while less aggregated studies find that unions have no net effect on measures of school performance. An important issue for many studies is that they tend to treat all teacher unions as identical by comparing student outcomes between union and non-union states or union and non-union school districts.

Unions differ in size and strength depending on local circumstances and history. Typical measures of teacher unionization such as dummy variables of union status implicitly treat all unions the same in the education production function. A 20 page collective bargaining agreement is likely to have fewer contract provisions that affect education than a 200 page agreement, ceteris paribus. Contract provisions affect the salaries of teachers, their working conditions, and employment security (Eberts and Stone, 1984), which in turn could influence student achievement positively or negatively.

In this empirical note, we contribute to this literature in two ways. First, we use the number of pages in a school district's teacher collective bargaining agreement as a proxy for union strength. Within Ohio, school district bargaining agreements vary from zero pages in a 
handful of small districts to 304 pages in Cleveland. Second, we employ Bayesian spatial econometric methods to deal with spatial dependence in school district activities. Our reducedform results indicate that collective bargaining directly lowers scores on high school math scores, but that the total effect is zero.

\section{Data and Model}

We employ a standard education production function approach (Hanushek, 1986). School district outputs such as test scores are a function of student, family, and school inputs into the educational process in these models. Despite the large literature on the effect of teachers unions on education production, few contemporary education production studies include a measure of unionization since in most states all districts are unionized. Similar to how studies on regulation use the page count of the Federal Register (Coffey et al., 2012), we measure union strength by the number of pages in a collective bargaining agreement.

Our data were hand collected from Ohio’s State Employment Relations Board in 2009 and represent conditions during the 2007-2008 school year. Since the number of contract provisions is not fixed, there is considerable variation across districts in the scale and scope of bargained working conditions. Some agreements involve only the salary schedule and basic benefits, while others go beyond these to include policies such as free admissions to school events or new faculty orientation. Our assumption is that the longer the contract, the more the contract represents union strength and control over the production of education. Theoretically, this could lead to higher or lower test scores and thus is an empirical question.

The remainder of our data comes from the Ohio Department of Education and are standard in the literature. Our dependent variable is the percentage of ninth graders passing the math proficiency exam in 
2008. Math was chosen over other exams due to its objective nature and because passage was a graduation requirement. We control for the number of teachers with fewer than 4 years of teaching experience, which has been found to negatively affect Ohio school district test scores (Hall, 2006). Other school inputs included are the average salary of classroom teachers in the district, the student to teacher ratio (Hall, 2007), and expenditure per pupil on administration (Anderson et al, 1991). Family and community variables included are median income per household and racial fractionalization. Hall and Leeson (2010) find that racial fractionalization is correlated with lower test scores.

Given the geographic nature of the data, it is reasonable to suspect that spatial autocorrelation may be an issue. Spatial autocorrelation is formally defined as follows (Anselin and Bera, 1998):

$$
\operatorname{cov}\left(y_{i}, y_{j}\right)=E\left(y_{i}, y_{j}\right)-E\left(y_{i}\right) E\left(y_{j}\right) \neq 0 \text { for } i \neq j
$$

where, $y_{i}$ and $y_{j}$ are observations on a random variable at locations $i$ and $j$ in space. The subscripts $i$ and $j$ can refer to any geographic designation and the equation implies non-independence of the random variable across space. Spatial autocorrelation can pose problems when using standard econometric techniques, such as OLS.

Spatial econometric models come in three basic varieties, the spatial autoregressive (SAR) model, the spatial error (SEM) model, and the spatial Durbin model (SDM). It should be noted that if OLS is used to estimate a model where the true data generating process (DGP) is the SAR, SEM, or SDM model, the regression parameter estimates can exhibit bias and inconsistency. The SAR model can be represented mathematically as follows:

$$
\begin{gathered}
y=\rho W y+X \beta+\varepsilon \\
\varepsilon \sim M V N\left(0, \sigma^{2} I_{n}\right)
\end{gathered}
$$

where $y$ is an $n \times 1$ vector of observations on the dependent variable, $W$ is an $n \times n$ spatial weight matrix, $X$ is an $n \times k$ matrix of explanatory variables, $\beta$ is a $k \times 1$ vector of regression coefficients, $\varepsilon$ is an $n \times 1$ vector of i.i.d. errors, and $\rho$ is the scalar spatial autocorrelation parameter. The SAR model is utilized 
when one believes that there may be spatial autocorrelation in the dependent variable. For example, it may be that school districts that are located in close proximity share certain characteristics, such that students' scores on standardized tests exhibit similarity.

The second type of spatial econometric model is the SEM model represented as follows:

$$
\begin{gathered}
y=X \beta+u \\
u=\lambda W u+\varepsilon \\
\varepsilon \sim M V N\left(0, \sigma^{2} I_{n}\right.
\end{gathered}
$$

where all symbols are defined as before, with the scalar $\lambda$ term representing the spatial autocorrelation parameter. The SEM model is similar to the OLS model with the exception that the SEM model has spatially autocorrelated errors. If the true DGP is the SEM model, use of OLS will results in incorrect standard errors for the regression coefficients.

The final spatial econometric model is the spatial Durbin model. The difference between the standard SAR model and the SDM model is the inclusion of spatially weighted independent variables, which can be expressed mathematically as follows:

$$
\begin{gathered}
y=\rho W y+X \beta \theta+\varepsilon \\
\varepsilon \sim M V N\left(0, \sigma^{2} I_{n}\right)
\end{gathered}
$$

where all of the definitions for the various parameters are as before for the SAR model. The exceptions are the $W$ and $X$ variables and the $\theta$ parameters, which represent spatially weighted explanatory variables and their respective coefficient estimates. LeSage and Pace (2009) show that the SDM model should be used when one believes that there may be omitted variables that follow a spatial process and are correlated with included independent variables. For a basic description of spatial econometric models, see LeSage (1997).

Our motivation for using Bayesian spatial econometric techniques, as opposed to the more familiar maximum likelihood paradigm, is that non-nested model comparisons can be examined in a statistically coherent manner. In our empirical application, we were uncertain about which model is the appropriate one, i.e. SAR vs. SEM. vs. SDM. We overcome this problem by calculating posterior model probabilities and 
choose the best model based on these calculations. Given our data, the SDM model has the highest posterior model probability at 99\%. More details regarding MCMC estimation of spatial econometric models is covered in LeSage and Pace (2009).

\section{Empirical Results}

Table 1 lists the direct, indirect or "spillover", and total effects from the SDM model. The second column of Table 1 lists the direct effects, which describe the corresponding change in the dependent variable in a district with a change in a particular explanatory variable in that same district. The results indicate the length of contract, racial fractionalization, and median income are directly significant. Our variable of interest, the length of contract, has a negative direct relationship with high school math scores. As for our empirical question of whether collective bargaining by teachers unions can benefit or harm school performance, it would seem that more stringent negotiations lead to less productive education production. The extent of this effect is limited to a particular district- the model does not exhibit a relationship between the length of one district's contract with the high school math scores of a surrounding district. This suggest that the effect of lengthy contracts in one district does not "spillover" to the education production in nearby districts. The results also indicate that the total global effect of contract length on test performance is zero. It should be pointed out that for local policymakers, however, the direct effect is likely to be more important.

The indirect effects of the explanatory variables on high school math scores are listed in the second data column of the table. This is where the spillovers of a particular district's characteristics on surrounding districts are examined. Racial fractionalization, average teacher salary, and teacher experience are each negative and significant. Unlike the length of contract, the scope of these variables reaches outside of a certain district. The total effects for racial fractionalization, average teacher salary, and teacher experience are also negative and significant, where the total effect for median income is positive and significant. 


\section{Conclusion}

In this letter we examine the impact of collective bargaining by teachers unions on the performance of high school students using the length of collective bargaining agreements. We add to the literature on collective bargaining and educational performance in two ways. First, we show that the length of collective bargaining agreements has information content with respect to education production. The direct effect of the number

of pages on Ohio school district math scores is negative. We do not find any spillovers, however, and the total effect is not statistically significant. Second, we account for the interrelated nature of school districts by using a Bayesian Durbin model. The significant indirect effects for teacher salaries, teacher experience, and racial fractionalization show the importance of accounting for spatial spillovers in education production. 


\section{References}

Anderson, G., Shughart, W., and Tollison, R. 1991. "Educational Achievement and the Cost of Bureaucracy.” Journal of Economic Behavior \& Organization 15(1): 29-45.

Anselin L., Bera, A. 1998. Spatial dependence in linear regression models with an introduction to spatial econometrics. In: Ullah A, Giles DEA (eds) Handbook of Applied Economic Statistics. Marcel Dekker, New York.

Coffey, B. P. McLaughlin and R. Tollison. 2012. “Regulators and Redskins.” Public Choice 153 (1-2): 191-204.

Eberts, R. 2007. “Teachers Unions and Student Performance: Help or Hindrance? Future of Children 17(1): 175-200.

Eberts, R., Stone, J. 1984. “Union Effects on Teacher Productivity.” Industrial and Labor Relations Review 37(3): 346-58.

Eberts, R., Stone, J. 1987. “Teacher Unions and the Productivity of Public Schools.” Industrial and Labor Relations Review 40(3): 354-63.

Hall, J. 2006. “The Dilemma of School Finance Reform.” Journal of Social, Political, and Economic Studies 31(2): 175.

Hall, J. 2007. "Local School Finance and Productive Efficiency: Evidence from Ohio.” Atlantic Economic Journal 35(3): 289-301.

Hall, J. and P. Leeson. 2010. "Racial Fractionalization and School Performance.” American Journal of Economics and Sociology 69(2): 736-758.

Hanushek, E. 1986. "The Economics of Schooling: Production and Efficiency in Public Schools.” Journal of Economic Literature 24(3): 1141-1177.

Hoxby, C. 2004. “How Teachers’ Unions Affect Education Production.” Quarterly Journal of Economics 111(3): 671-718.

LeSage, J. 1997. Regression analysis of spatial data. Journal of Regional Analysis and Policy 27, 83-94.

LeSage, J., Pace, R. 2009. Introduction to spatial econometrics. CRC Press, Boca Raton.

Peltzman, S. 1993. "The Political Economy of the Decline of American Public Education.” Journal of Law and Economics 36(1): 331-70. 